\title{
ONE YEAR STUDY OF LYING AND STANDING BEHAVIOUR OF DAIRY COWS IN A FRESTALL BARN IN ITALY
}

\author{
Giorgio Provolo, Elisabetta Riva
}

\section{Introduction}

The design of cowsheds for dairy cows points often the attention more on functional aspects, optimizing spaces and management of the herd, disregarding in most cases some elements which influence the environmental conditions [Riva 2005]. This aspect has been faced by many international authors who have pointed out the negative effect on the productivity of the animals in relation to environmental stress conditions [Armstrong 1994; Kadzere 2002; Bouraoui 2002; West 2003]. Even from studies related to the italian situation it has been pointed out the necessity to create a comfortable environment also from the climatic point of view [Cascone 2005; Liberati 2005; D’Archivio 2007].

To improve the knowledge of the influence of the climatic parameters on animal welfare conditions a research has been carried out in a barn which has highlighted an anomalous behaviour of the herd. During the daytime, indeed, these prefer to stay only in the north side of the cowshed and refuse the southwards part. On the other hand, during the night time the dairy cows take up regularly the cowshed. This behaviour is more evident during the summer time. The underuse of the structure and the problems related to the herd have suggested to investigate the correlation of animals behaviour with the climatic parameters of the barn in a long term-lasting study, according to the outcomes of other works [Overton 2002].

\section{Materials and methods}

The study, begun in June 2004 and lasted 13 months, has been carried out in dairy cattle farm in the province of Lodi in a free stall cowshed. The rein-

Paper received 23.04.2008; accepted 31.01.2009

Dr. Giorgio Provolo, associate professor; Dr. Elisabetta Riva, Postdoctoral Fellow Dipartimento di Ingegneria Agraria, Università degli Studi di Milano, via Celoria, 220133 Milano Italia. giorgio.provolo@unimi.it forced concrete precast structure has a rectangular layout of the dimensions $52 \times 17.6 \mathrm{~m}$ with a northsouth oriented longitudinal axis and asymmetric gable roof, parallel to the longitudinal axis of the cowshed, and open ridge. The west pitch slope is $7.5 \%$, while the east one is $10 \%$.

The building is without outside main wall and borders on the east side with an other building partially closed. The barn is equipped with three axial flow fans $(1.27 \mathrm{~m}$ diameter, $0.75 \mathrm{~kW})$ placed above the stalls.

Figure 1 shows the microclimatic sensors and video cameras installation scheme in the barn, provided with 74 stalls placed on two lines head to head.

The data loggers for the measurement of the temperature were located between the stall rows at a height of about $1.2 \mathrm{~m}$ about the floor in order to measure the air temperature as close as possible to the animals, but without been affected by the closeness of the animal self. Two air-speed indicators and two sensors of temperature and humidity (weather stations Heavy Weather WS) have been installed over the feed manger using plastic pipes fixed to the roof beam in order to positioning them at a height of $2 \mathrm{~m}$ from the animals floor, so that they can not be reached by the cows. The air-speed indicators have been positioned at $15 \mathrm{~m}$ from the cowshed's end as regard to north and south and the sensors of temperature and humidity at $7.5 \mathrm{~m}$ from the same reference. The used instrumentation has allowed the continuous measurement of the different parameters. The microclimatic data interval time recording was set at 30 minutes. The black-andwhite cameras are provided with a sheltered container and a $3.6 \mathrm{~mm}$ lens. The mini lens provides a shot angle of about $67^{\circ}$ and uses a CCD sensor of $1 / 3$ inch. The cameras are connected to a 4 channels video capture card $D V R 4200$ integrated in a personal computer able to perform an analogue to digital conversion of the signal for the subsequent storage on a hard disk.

The digital video recording parameters have been set, thanks to the suited control software with a capture frequency of a frame per second. This value has been chosen as compromise between the possibility of maintaining a good comprehension of the animals 


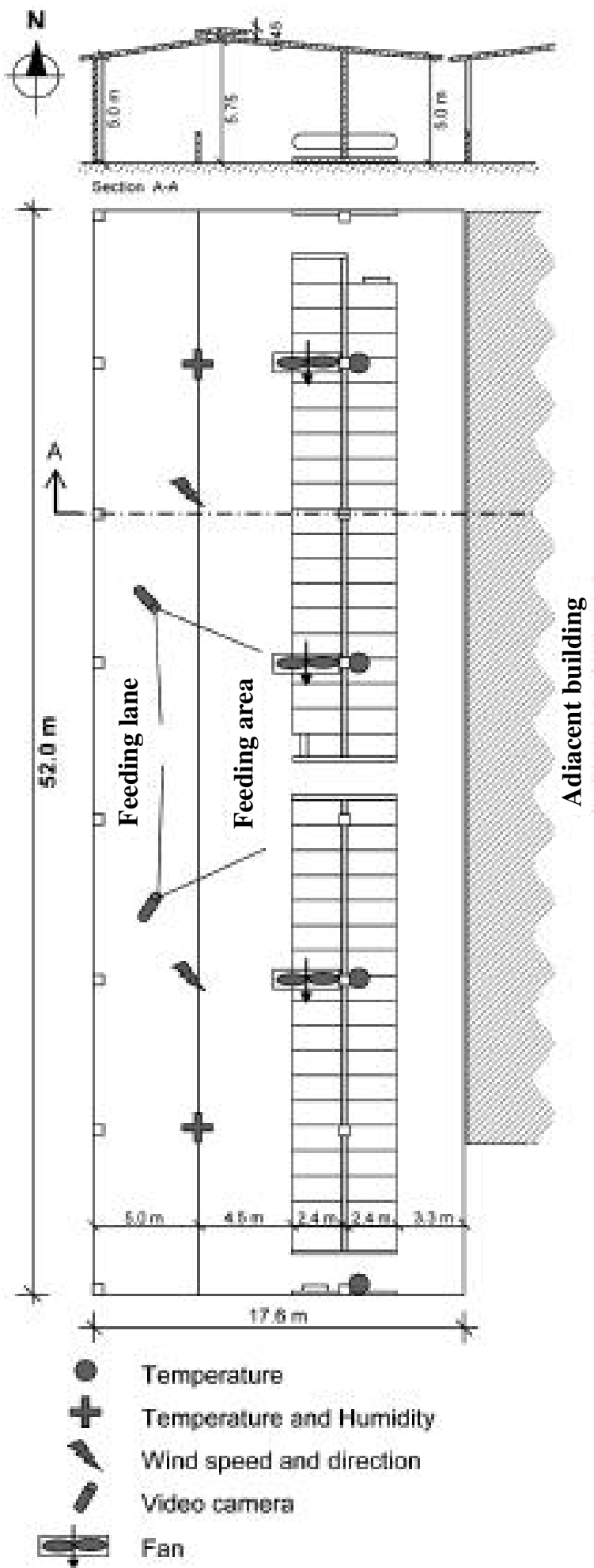

Fig. 1 - Plan and cross section of the cowshed with the location of the sensors and of the two video cameras with related shoot angles.

movement and the size of the information to save. Data related to the trend of the local weather conditions were used to be compared with the internal microclimatic data.

Data from the two ARPA's network weather stations of Sant'Angelo Lodigiano and Cavenago d'Adda were used for this purpose, which report hourly: temperature, relative humidity, global sun radiation, wind speed and direction, rainy condition. The analysis of the video recording data consisted in the evaluation of the number of dairy cows engaged in the different activities (feeding or drinking, resting, inactive standing), and subdividing them in the two sides (north and south) of the structure.

The time base used for the video analysis in order to extract the animals behaviour has been analyzed by Mitlohner [2001] who pointed out that in order to measure short time events (e.g. the drinking) it is necessary to use limited scanning periods (10 minutes), but that other behaviours, such as resting, can be adequately explained with scanning to 30-60 minutes. Also Frazzi [2000] have used an hourly analysis frequency of the animals behaviour in order to compare the effect of different barn cooling systems. On the base of this experiences the videotapes have been analyzed hourly.

For the further processing of the collected data some microclimatic and animals behaviour indices have been defined. Concerning the climatic aspects the Temperature Humidity Index (THI), widely utilized in bibliography, has been used to consider jointly temperature and humidity. It was calculated with the relation suggested by ASABE [2006]:

$$
\mathrm{THI}=\mathrm{tba}+0.36 \mathrm{tpr}+41.2
$$

Where:

THI = Temperature Humidity Index

$\mathrm{t}_{\mathrm{ba}}=$ dry bulb temperature $\left({ }^{\circ} \mathrm{C}\right)$

$\mathrm{t}_{\mathrm{pr}}=$ dew point temperature $\left({ }^{\circ} \mathrm{C}\right)$

Other have been used for the analysis of the data related to the behaviour. The first of these indices is related to the number of animals resting in the stall:

$$
\mathrm{CLI}=\frac{\text { cows lying in stalls }}{\text { total cows }}
$$

where:

\section{CLI=Cow Lying Index}

It represents one of the aspects of animal comfort and it is connected to the number of animals in the stall in comparison with the total number of heads [Cook 2005].

Likewise are defined the index for the standing animals and the one which measures the cow tendency to move to the northern part of the building:

$$
\mathrm{CSI}=\frac{\text { cows standing }}{\text { total cows }}
$$

where:

$\mathrm{CSI}=$ Cow Stress Index

$$
\mathrm{NCl}=\frac{\text { cows in the north side }}{\text { total cows }}
$$

where:

$\mathrm{NCI}=$ North Cow Index 
The data collected during the testing have been inserted in a database and have been organized in order to make the information homogeneous as time basis. This has required the calculation of hourly average values starting from the temperature and humidity data registered each half an hour.

A preliminary analysis of hourly data indicated the day times in which the animals did not suffer perturbations from the farm management (milking and feeding) and highlighted the uniform behaviour of cows all the year long during the evening and night hours. Therefore, in order to obtain daily values for the environmental data inside and outside the structure, hourly data have been used, from 9.00 a.m. to 10.00 p.m. excluding the period form 5.00 to 7.00 p.m.. The data have been processed in order to obtain the parameters reported in table 1 , where it is also synthesized the calculation method. Maximum and minimum THI parameters have been used besides the daily averages [St-Pierre 2003]. Finally the coefficients of linear correlation between the indices of dairy cows behaviour and the single environmental factors have been calculated.

The results are reported for the whole period and for daily THI values over and below the value of 60 .

\section{Results and discussion}

The average values and the standard deviation obtained for the behavioural indices, reported in table 2, point out that the use of stalls (CLI) in the examined barn is limited, with an average value of $51 \%$. Also considering the total number of cows lying in free stalls divided by the total of cows not eating (stall-use

\begin{tabular}{|c|c|c|}
\hline & unit & Calculation Method \\
\hline THIi & & Internal THI average value \\
\hline $\mathbf{T i}$ & ${ }^{\circ} \mathrm{C}$ & Internal Temperature average value \\
\hline THI max & & $\begin{array}{l}\text { THI calculated with the highest daily } \\
\text { temperature and the lowest Relative } \\
\text { Humidity }\end{array}$ \\
\hline THI min & & $\begin{array}{l}\text { THI calculated with the lowest daily } \\
\text { temperature and the highest Relative } \\
\text { Humidity }\end{array}$ \\
\hline RG & W. $\mathrm{m}^{-2}$ & $\begin{array}{l}\text { Average value of the hourly Global } \\
\text { Radiation }\end{array}$ \\
\hline Te & ${ }^{\circ} \mathrm{C}$ & $\begin{array}{l}\text { Average value of the external hourly } \\
\text { temperature }\end{array}$ \\
\hline THIe & & Hourly external THI average value \\
\hline Raine & $\mathrm{mm}$ & $\begin{array}{l}\text { Average value of the hourly rainy } \\
\text { condition }\end{array}$ \\
\hline Ws & $\mathrm{m} \cdot \mathrm{s}^{-1}$ & Average value of the hourly wind speed \\
\hline Wd & $\circ$ & $\begin{array}{l}\text { Average value of the hourly wind } \\
\text { direction }\end{array}$ \\
\hline $\begin{array}{l}\text { Sun } \\
\text { Height }\end{array}$ & $\circ$ & $\begin{array}{l}\text { Maximum angle of the sun on the } \\
\text { horizon during a day }\end{array}$ \\
\hline
\end{tabular}

TABLE 1 - Daily climatic parameters obtained by the hourly parameters and used calculation method. index) the value obtained of $66 \%$ is still below the goal of $75 \%$ even if we consider the variability during the day [Overton 2003].

Also concerning the NCI, the average values confirm the considerable trend of the dairy cows to occupy the northern zone. Indeed this side of the barn houses averagely $20 \%$ of dairy cows more than an homogeneous distribution.

The cows eating or drinking are, for difference about a fourth of the herd, average value which hides however a high variability during the day.

In table 2 it is also possible to notice that the temperature average values during the survey period are of $15.1^{\circ} \mathrm{C}$ inside and $13.8{ }^{\circ} \mathrm{C}$ outside, corresponding to the values of THI of 59.4 inside and of 58.1 outside.

Table 3 reports the results of the analysis of the correlations between environmental parameters and the behaviour indices and points out the highly significant connections for almost all the considered parameters (with the exception of the rainy condition). The strength of the correlation turns out however differentiated in the different analyses.

A group of parameters is deeply correlated with the animals behaviour with correlation coefficient ( $\mathrm{r}$ ) values higher than 0.8. To this group belong all the factors directly influenced by the temperature (external, internal temperature and THI). A second group is set up by parameters whose $r$ value is included between 0.5 and 0.8 and it is represented by the measures of global radiation, and sun height. Finally, a last set of correlations, whose $r$ value is limited, groups the other climatic values (wind speed and direction and rainy condition). These results point out how the values of temperature or THI might be sufficient by their own to explain for a good part the variations of the behaviour indices during the year. Indeed the correlation co-

\begin{tabular}{lcccccc}
\hline & \multicolumn{2}{c}{$\begin{array}{c}\text { All values } \\
(\mathbf{n}=\mathbf{2 7 0})\end{array}$} & \multicolumn{2}{c}{ THI $<\mathbf{6 0}$} & \multicolumn{2}{c}{ THI $\geq \mathbf{6 0}$} \\
& $\bar{x}$ & $\boldsymbol{s} \boldsymbol{d}=\mathbf{1 1 7})$ & $\bar{x}$ & $\boldsymbol{s} \boldsymbol{d}$ & $\bar{x}$ & $\boldsymbol{s} \boldsymbol{d}$ \\
\hline CLI & 0.51 & 0.14 & 0.63 & 0.08 & 0.42 & 0.09 \\
CSI & 0.26 & 0.13 & 0.15 & 0.05 & 0.35 & 0.09 \\
NCI & 0.70 & 0.14 & 0.56 & 0.06 & 0.80 & 0.10 \\
THIi & 59.41 & 11.01 & 48.90 & 5.92 & 68.41 & 4.39 \\
Ti & 15.11 & 8.47 & 7.00 & 4.36 & 22.06 & 3.48 \\
THI max & 63.84 & 11.59 & 52.92 & 6.23 & 73.19 & 5.11 \\
THI min & 55.03 & 10.30 & 45.33 & 5.99 & 63.33 & 4.08 \\
RG & 165.71 & 102.78 & 94.68 & 65.68 & 226.50 & 88.92 \\
Te & 13.84 & 8.96 & 5.28 & 4.62 & 21.17 & 3.78 \\
THIe & 58.09 & 11.50 & 47.15 & 6.20 & 67.45 & 4.69 \\
raine & 0.07 & 0.22 & 0.08 & 0.21 & 0.06 & 0.22 \\
Ws & 0.90 & 0.62 & 0.65 & 0.55 & 1.11 & 0.59 \\
Wd & 185.96 & 66.83 & 200.81 & 67.15 & 173.25 & 64.03 \\
Sun Height & 48.25 & 17.02 & 32.94 & 11.25 & 57.88 & 11.50 \\
\hline & & & & & &
\end{tabular}

TABLE 2 - Average values $(\bar{x})$ and standard deviation $(s d)$ of the daily climatic parameters and the behaviour indices. 


\begin{tabular}{lccc}
\hline & CLI & CSI & NCI \\
\hline THIi & $-0.882(* *)$ & $0.879(* *)$ & $0.868(* *)$ \\
Ti & $-0.879(* *)$ & $0.877(* *)$ & $0.864(* *)$ \\
THI max & $-0.875(* *)$ & $0.870(* *)$ & $0.849(* *)$ \\
THI min & $-0.859(* *)$ & $0.856(* *)$ & $0.856(* *)$ \\
RGe & $-0.566(* *)$ & $0.574(* *)$ & $0.513(* *)$ \\
Te & $-0.878(* *)$ & $0.876(* *)$ & $0.863(* *)$ \\
THIe & $-0.878(* *)$ & $0.876(* *)$ & $0.866(* *)$ \\
Raine & 0.076 & -0.087 & -0.056 \\
Wse & $-0.280(* *)$ & $0.289(* *)$ & $0.353(* *)$ \\
Wde & $0.236(* *)$ & $-0.293(* *)$ & $-0.283(* *)$ \\
Sun Height & $-0.675(* *)$ & $0.686(* *)$ & $0.632(* *)$ \\
\hline$* *$ The correlation is significant at level 0.01. &
\end{tabular}

TABLE 3 - Values of the correlation coefficient between the considered environmental parameters and the daily animals behaviour indices (all values $n=270$ ).

efficients related to THI or temperature have values of around 0.85 . The corresponding coefficients of determination are over 0.7 thus, more than $70 \%$ of the total variance can be accounted for by the linear fit.

Considering only the days with average THI lower then 60 , the values of the correlation coefficient decrease but maintain a highly significance of the linear fit for the temperature related parameters (table 4). When THI is low, the global radiation does not seem to be correlated to lying and standing behaviour of cows, but a significant influence on the NCI is still evidenced.

In agreement to literature, the effect of climatic variations on behaviour indices is more evident at higher values of THI. Table 5, reporting the values obtained considering the days with THI values above

\begin{tabular}{lccc}
\hline & CLI & CSI & NCI \\
\hline THIi & $-0.548(* *)$ & $0.483(* *)$ & $0.473(* *)$ \\
Ti & $-0.514(* *)$ & $0.482(* *)$ & $0.498(* *)$ \\
THI max & $-0.528(* *)$ & $0.437(* *)$ & $0.394(* *)$ \\
THI min & $-0.515(* *)$ & $0.490(* *)$ & $0.505(* *)$ \\
RGe & 0.048 & -0.181 & $-0.200(*)$ \\
Te & $-0.495(* *)$ & $0.428(* *)$ & $0.414(* *)$ \\
THIe & $-0.512(* *)$ & $0.455(* *)$ & $0.443(* *)$ \\
Raine & -0.067 & 0.026 & 0.107 \\
Wse & 0.036 & -0.017 & 0.073 \\
Wde & -0.053 & -0.021 & -0.083 \\
Sun Height & -0.065 & -0.046 & -0.046 \\
\hline
\end{tabular}

** The correlation is significant at level 0.01 .

* The correlation is significant at level 0.05 .

TABLE 4 - Values of the correlation coefficient between the considered environmental parameters and the daily animals behaviour indices $(\mathrm{THI}<60 \mathrm{n}=117)$.
60, shows high significance for all parameters related to temperature. However, it can be noticed that the correlation coefficient related to internal THI is higher then the one related to internal temperature. This difference confirms that the THI, including the effect of humidity, is a more effective parameter in summer conditions.

Figure 2 reports the trend of the THI and CLI daily data during the study period. It can be observed how acceptable values are reached in a short period only during the winter, despite THI shows values below the threshold of 72 considered critical [Armstrong 1994], for a more extended period.

Likewise in figure 3 it is observable how the tendency of the dairy cows to occupy the northern zone of the building, enhanced in the summer months, decreases only in a short period of the year.

However the behavioural indices do not seem to answer to the daily environmental variations, but rather they show trends which follow the seasonal trend.

\begin{tabular}{lccc}
\hline & CLI & CSI & NCI \\
\hline THIi & $-0.738(* *)$ & $0.788(* *)$ & $0.650(* *)$ \\
Ti & $-0.641(* *)$ & $0.688(* *)$ & $0.594(* *)$ \\
THI max & $-0.695(* *)$ & $0.738(* *)$ & $0.573(* *)$ \\
THI min & $-0.632(* *)$ & $0.676(* *)$ & $0.589(* *)$ \\
RGe & $-0.248(* *)$ & $0.262(* *)$ & 0.076 \\
Te & $-0.739(* *)$ & $0.775(* *)$ & $0.634(* *)$ \\
THIe & $-0.737(* *)$ & $0.779(* *)$ & $0.654(* *)$ \\
Raine & $0.185(*)$ & -0.156 & -0.127 \\
Wse & 0.068 & -0.053 & 0.060 \\
Wde & 0.076 & $-0.169(*)$ & -0.106 \\
Sun Height & $-0.314(* *)$ & $0.357(* *)$ & 0.131 \\
\hline
\end{tabular}

** The correlation is significant at level 0.01 .

* The correlation is significant at level 0.05 .

TABLE 5 - Values of the correlation coefficient between the considered environmental parameters and the daily animals behaviour indices $(T H I \geq 60 n=153)$.

\section{Conclusions}

The results of the study highlight how cow behaviour is expressively different during the year and is influenced by the external climatic conditions, particularly by THI.

The obtained results suggest the necessity to deepen further the studies in order to obtain design information for the new structures in relation to the local climatic conditions. Moreover, a more careful design might reassess the role of the "structure" also in terms of delay time and reduction factor of the heat wave, especially in summer time, since the THI daily average values do not exceed the moderate stress conditions. 


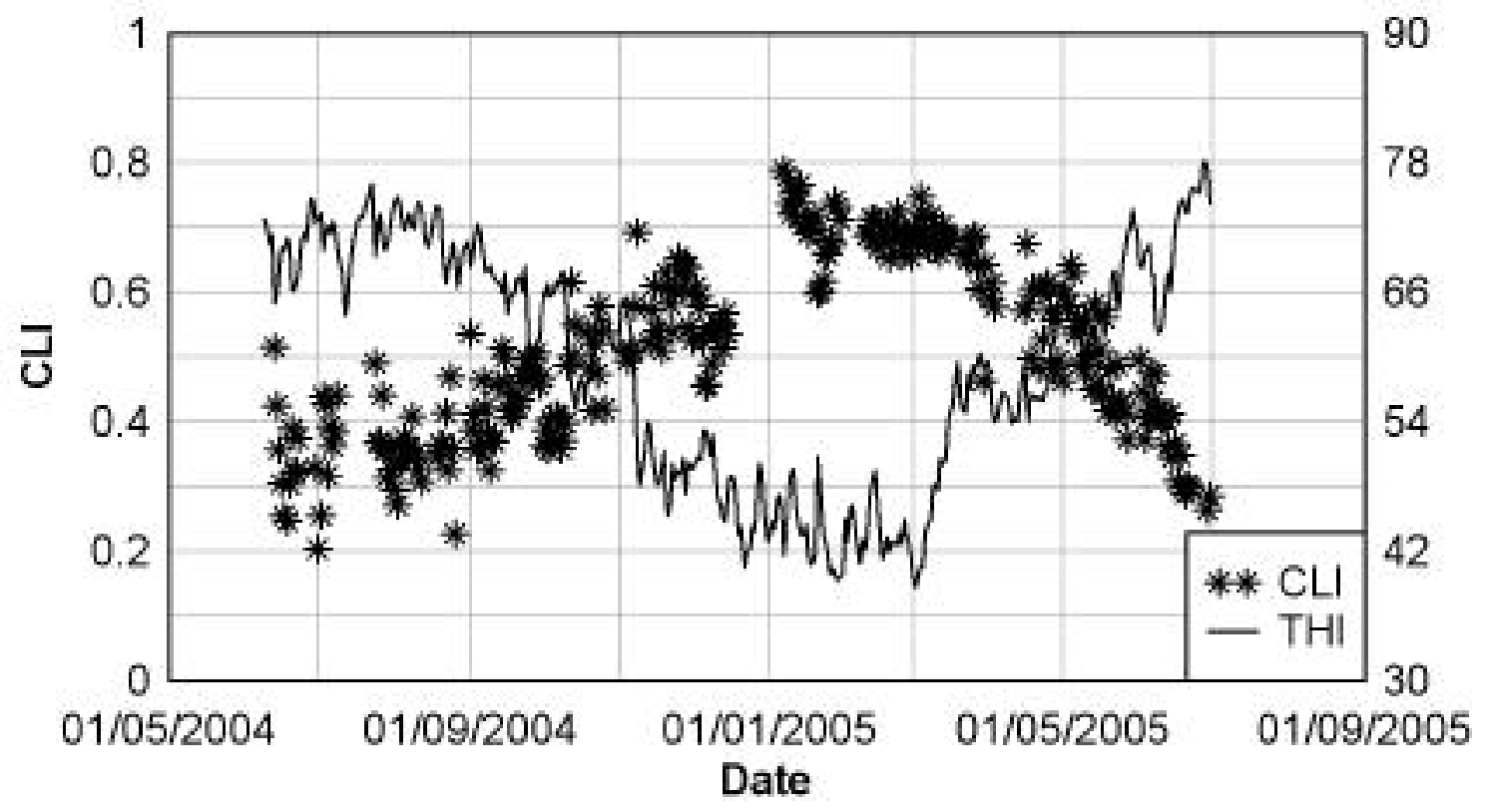

폰

Fig. 2 - Trends of the THI and CLI daily data during the study period.

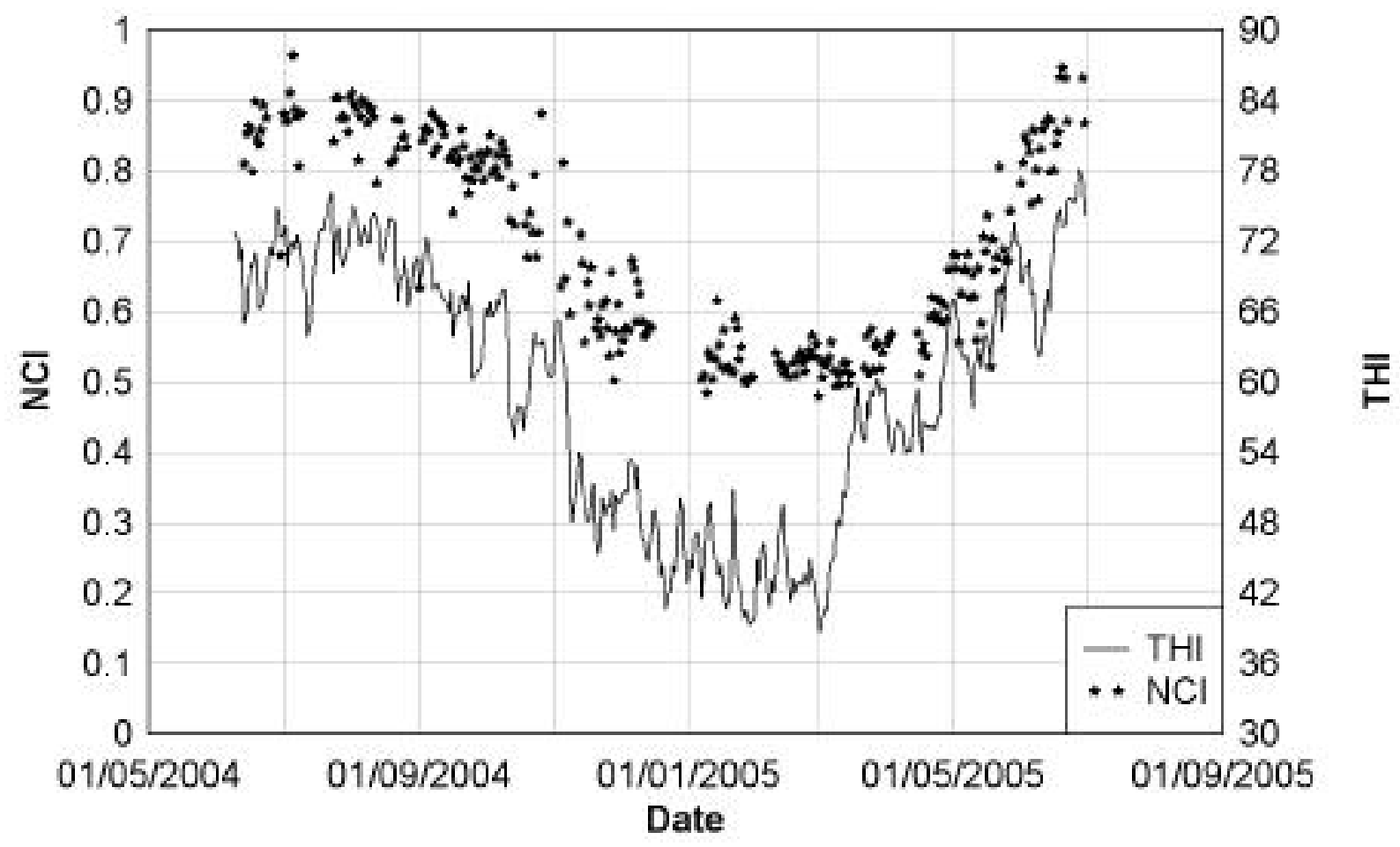

Fig. 3 - THI and NCI daily data trends during the study period.

Of course the design should consider all those aspects which are already consolidated, but actually insufficiently acknowledged, related to: the building orientation; the minimum distance from other buildings in order to guarantee a suitable ventilation, the realization of roof with suitable slopes for assuring a good natural ventilation. Design criteria of the resting and feeding area are also to be taken into consideration.

In the monitored cowshed some lacks in the design were noticed. Indeed the structure has been realized with a north-south longitudinal axes orientation and the ventilation is limited by the nearby building. This 
choice has been suggested by the available space in the farm more than by the mentioned design criteria. Moreover, the roof slope and its shape make the stack system of natural ventilation ineffective.

In addition the forced ventilation system in the cowshed placed in the resting area do not cover the feeding area and it is under-sized for the cowshed requirements.

The preference of the cows to stay during the day only in the north side of the cowshed and refuse the southwards part, might be attributed to the insufficient ventilation and to the exposition of the south side to direct radiation.

The use of behaviour indices seems to be effective for the evaluation of cowshed performances. The correlation between CLI and THI is in agreement with literature. However, similar results have been obtained for the NCI. If the results obtained will be confirmed by further researches, the use of an index expressing the number of animals in the different sides of the barn might be a more practical way to check the barn design and the functionality of ventilation systems in actual conditions.

The investigation method used, based on the video recording and the images post-analysis allowed to obtain a detailed evaluation of the animals behaviour during the day. This result was achievable only thanks to the integration between electronics and information technology which has reached for the used equipment a high level of effectiveness and a considerable costs reduction.

However this approach maintains some limiting characteristics connected to the necessity of installations inside livestock buildings with problems of protection from environmental conditions and requirement of frequent maintenance. Indeed, mostly during the summer time it was necessary to clean weekly the video cameras' lenses, soiled by the flies. Moreover the necessity of a connection to the electric network to supply the monitoring system makes the equipment sensitive to the tension variation connected with the terminal tracts of the network or to supply interruptions caused by meteorological events.

Finally, the methodology used is considerably requiring in terms of human resources in relation to the image analysis of the animals behaviour which can not, at the current condition of the technology, be easily automated. Moreover, some experiences have already pointed out the feasibility of the complete automation of the monitoring both of the animals position inside the cowshed and of the activities they are carrying out. The development of these technologies will provide a further significant contribution to the research on the cow behaviour which will allow the design of livestock production facilities more suitable to the animals needs and respectful of their welfare.

\section{References}

Armstrong D.V., Heat Stress Interaction with Shade and Cooling, Journal of Dairy Science, 1994, 77 (7), 20442050.

ASABE, Design of Ventilation Systems for Poultry and Livestock Shelters, in ASAE EP270.5, FEB03 Standards, 2006, 53rd Edition, American Society of Agricultural and Biological Engineers, St. Joseph, Michigan (USA), 652-670.

Bouraoui R., Mondher Lahmar. Majdoub A., Djemali M. Belyea R., The relationship of temperature-humidity index with milk production of dairy cows in a Mediterranean climate, Animal Research, 2002, 51 (6), 479-491.

Cascone G., D'Emilio A., Mazzarella R., Criteri di progettazione e gestione delle apertura di ventilazione nelle stalle per bovine da latte mediante un modello CFD (Design and management methods for the ventilation openings in dairy housing by a CFD model), Atti del Convegno "L'ingegneria agraria per lo sviluppo sostenibile dell' area mediterranea", (2005), Catania.

Cook N.B., Bennett T.B., Nordlund K.V., Monitoring indices of cow comfort in free-stall-housed dairy herds, Journal of Dairy Science, 2005, 88 (11), 3876-3885.

D’Archivio S., Zappavigna P., Come la temperatura può influenzare la mandria (How the temperature can affect the herd), L'informatore zootecnico, 2007, 13, 28-40.

Frazzi E., Calamari L., Calegari F., Stefanini L., Behavior of dairy cows in response to different barn cooling systems, Transactions of the ASABE, 2000, 43 (2), 387-394.

Kadzere C.T., Murphy M.R., Silanikove N., Maltz E., Heat stress in lactating dairy cows: a review, Livestock Production Science, 2002, 77 (1), 59-91.

Liberati P., Zappavigna P., A computer model for optimisation of the internal climate in animal housing design, Livestock Environment VII. Proceedings of the Seventh International Symposium, 2005, Beijing, China.

Mitlohner F.M., Morrow-Tesch J.L., Wilson S.C., Dailey J.W., Mcglone J.J., Behavioural sampling techniques for feedlot cattle, Journal of Animal Science, 2001, 79 (5), 1189-1193.

Overton M.W., Sischo W.M., Temple G.D., Moore D.A., Using time-lapse video photography to assess dairy cattle lying behaviour in a free-stall barn, Journal of Dairy Science, 2002, 85 (9), 2407-2413.

Overton M.W., Moore D.A., Sischo W.M., Comparison of commonly used indices to evaluate dairy cattle lying behaviour, Proceedings of the Fifth International Dairy Housing Conference ASAE Publication Number 701P0203, 2003, 125-130.

Riva E., De Marco R., Provolo G., Analisi degli interventi strutturali finanziati dal piano di sviluppo rurale in provincia di Lodi (Analysis of structural interventions financed by the Rural Development Plan in the province of Lodi), Atti del Convegno "L'ingegneria agraria per lo sviluppo sostenibile dell'area mediterranea", 2005, Catania.

St-Pierre N.R., Cobanov B., Schnitkey G., Economic Losses form Heat Stress by US Livestock Industries, Journal of Dairy Science, 2003, 86 (E. Suppl.), E52-E77.

West J.W., Effects of heat-stress on production in dairy cattle, Journal of Dairy Science, 2003, 86 (6), 2131-2144. 


\section{SUMMARY}

Dairy farm buildings can have, as it is well known, a big influence on the microclimatic conditions in the cowshed. In order to examine the influence of environmental parameters on the conditions affecting animal welfare, an experimental programme was set up at a farm where anomalous behaviour of cows had been previously noted.

The research was carried out in a freestall barn from June 2004 till June 2005. Part of the research involved a detailed monitoring of animal movements and a simultaneous measurement of temperature and humidity within the cowshed. The behaviour of cows has been obtained by the analysis of a recorded video and expressed through indices. A strict relationship between environmental parameters and animal movement has been confirmed by the results obtained. The proportion of animals resting in stalls during the daytime, not affected by milking or feeding, rised from $30 \%$ in hot periods to $75 \%$ in winter time. The highly significant $(\mathrm{P}<0.01)$ correlation obtained between environmental parameters and cow behaviour confirmed the strong influence of THI on total proportion of lying cows. However, the variation in cow behaviour when temperature values were inside the range considered optimal for cows, suggests the influence of other parameters, like direct radiation.

Keywords: Dairy cow, Behaviour, THI, videorecording analysis. 
004_Provolo(534)_27 3-09-2009 14:36 Pagina 34 